\title{
A study on correlation between laterality of placenta on mid trimester ultrasonography and perinatal outcome
}

\author{
Avik Ghosh ${ }^{1}$, Mrinalkanti Ghosh ${ }^{2 *}$ \\ ${ }^{1}$ Department of Obstetrics and Gynecology, ${ }^{2}$ Department of Radiodiagnosis, Burdwan Medical College, Purba
} Bardhman, West Bengal, India

Received: 12 October 2019

Revised: 19 November 2019

Accepted: 28 November 2019

*Correspondence:

Dr. Mrinalkanti Ghosh,

E-mail: dravik6@gmail.com

Copyright: $\odot$ the author(s), publisher and licensee Medip Academy. This is an open-access article distributed under the terms of the Creative Commons Attribution Non-Commercial License, which permits unrestricted non-commercial use, distribution, and reproduction in any medium, provided the original work is properly cited.

\section{ABSTRACT}

Background: Fetus is dependent on placenta for supply of nutrients from mother. Objective of this study was to assess the relationship between laterality of placenta by mid-trimester ultrasonography and perinatal outcome.

Methods: It was a prospective observational study conducted between June 2016 to June 2017 at Burdwan Medical College, West Bengal. Participants were uncomplicated pregnant women having 18-24 weeks gestation attending antenatal clinics and admitted in ward who underwent obstetric sonography including placental localization. Women were observed till delivery. Analysis was done for site of implantation of placenta and its correlation with perinatal outcome.

Results: Total of 300 women considered for the study, 195/300 (65\%) had central implantation of placenta and $105 / 300(35 \%)$ had lateral type of placentation. There were 4 IUFDs (1.33\%); 2 (1.03) with central placenta and 2 (1.9) with lateral placenta. Among $31(10.33 \%)$ IUGR babies $13(6.67 \%)$ were associated with central and 18 (17.14\%) with lateral placenta. Among $27 \mathrm{LBW}$ babies 16 (8.21\%) were related to central placenta and $11(10.48 \%)$ were related to lateral placenta. Among 57 SNCU admissions 26 (13.33\%) were related to central placenta and 31 $(29.52 \%)$ were related to lateral placenta. Average birth-weight is $2.6 \pm 0.31 \mathrm{~kg}$ and $2.51 \pm 0.26 \mathrm{~kg}$, respectively for central and lateral placenta.

Conclusions: Laterally located placenta is associated with relatively poor perinatal outcome compared to central placenta with increased rates of IUGR, IUFD and LBW babies.

Keywords: Perinatal outcome, Placental location, Preeclampsia, Ultrasonography

\section{INTRODUCTION}

Fetus is dependent on placenta for supply of nutrients from mother. Therefore, fetal survival and growth are largely dependent on placenta. When the placenta is laterally located (defined as $75 \%$ or more of placental mass located on one side of midline), the uterine artery distal to the placenta has higher resistance than the opposite side because of less trophoblastic invasion into spiral arteriole. In women with centrally located placentas, both uterine arteries demonstrate similar resistance. ${ }^{1,2}$ Thus, there is overall increase in resistance of placental vascular bed. Women with laterally located placenta are thus more prone to have foetuses with IUGR, IUFD and LBW. ${ }^{3}$ These women are also more prone to develop preeclampsia. ${ }^{1}$ The present study of placental localization by ultrasound at $18-24$ weeks was done to find out incidence of laterally situated placenta in a selected cohort and its association with perinatal outcome. 
Objective of this study was to find out whether placental laterality as determined by ultrasonography can be used as a predictor of perinatal outcome.

\section{METHODS}

It was a prospective observational study conducted at Burdwan Medical College and Hospital for a period extending from June 2016 to June 2017 after receiving ethical clearance from the clinical research ethics committee. Total 300 pregnant women at their 18-24 weeks of gestations including those attending antenatal clinic and ward admissions were included in the study after taking informed consent from them.

\section{Exclusion criteria}

- Pregnant women with high-risk factors like chronic hypertension or essential hypertension, diabetes mellitus, thyrotoxicosis, renal disease, severe anaemia, connective tissue disorder, positive lupus anticoagulant and anticardiolipin antibodies, twin pregnancy was excluded.

The location of placenta was determined by sonography and classified as central or lateral. They were followed up subsequently to assess perinatal outcome.

\section{Statistical analysis}

Statistical analysis was done by percentage, chi-square test, $\mathrm{p}$ value, mean etc. $\mathrm{p}$-value $<0.05$ was considered statistically significant.

\section{RESULTS}

Out of 300 women included in the study $195(65 \%)$ had central and $105(35 \%)$ had lateral placenta. $42(14 \%)$ women developed preeclampsia. Among them 25 $(23.82 \%)$ had lateral placenta and $17(8.72 \%)$ had central placenta (p-value 0.000) depicted in Table 1.

Table 1: Relationship between placental location and preeclampsia.

\begin{tabular}{|lllllll|}
\hline & & \multicolumn{2}{c}{ Placental location } & Total & p-value & Significance \\
\cline { 2 - 7 } Preeclampsia & No & $178(91.28)$ & $80(76.19)$ & $258(86)$ & \multirow{2}{*}{0.000} & \multirow{2}{*}{ Significant } \\
\cline { 2 - 7 } & Yes & $17(8.72)$ & $25(23.81)$ & $42(14)$ & \\
\hline Total & & $\mathbf{1 9 5}(\mathbf{1 0 0})$ & $\mathbf{1 0 5}(\mathbf{1 0 0})$ & $\mathbf{3 0 0}(\mathbf{1 0 0})$ & & \\
\hline
\end{tabular}

Table 2: Relationship between placental location and eclampsia.

\begin{tabular}{|lllllll|}
\hline & & \multicolumn{2}{c}{ Placental location } & Total & p-value & Significance \\
\cline { 1 - 6 } Eclampsia & No & $187(95.9)$ & $91(86.67)$ & $278(92.67)$ & \multirow{2}{*}{0.003} & Significant \\
\cline { 2 - 6 } & Yes & $8(4.1)$ & $14(13.33)$ & $22(7.33)$ & & \\
\hline Total & & $195(100)$ & $105(100)$ & $300(100)$ & & \\
\hline
\end{tabular}

Table 3: Relation between placental location and perinatal outcome.

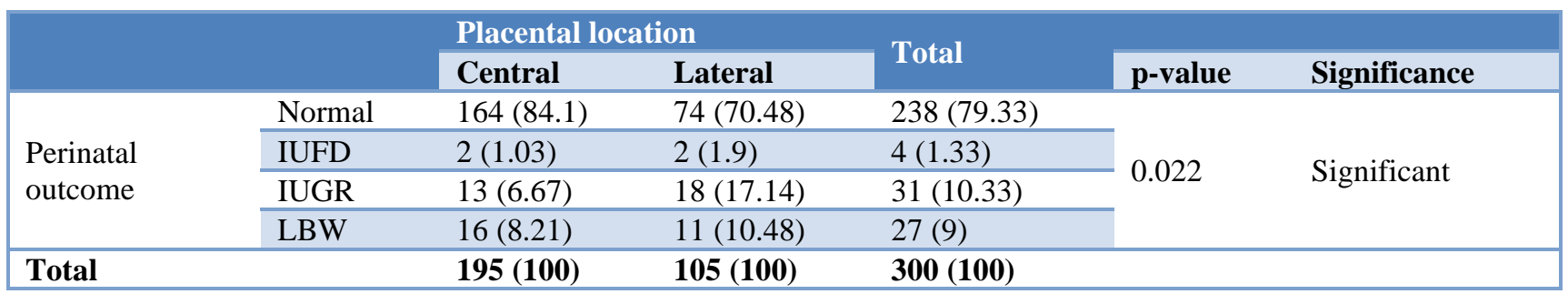

A total $22(7.33 \%)$ women developed eclampsia of which $14(13.33 \%)$ had lateral and $8(4.1 \%)$ had central placenta (p-value 0.003). This is elaborated in Table 2. This clearly suggests that lateral placenta is more commonly associated with preeclampsia-eclampsia than its counterpart.
Among 4 IUFD (intrauterine fetal death) babies delivered $2(1.03 \%)$ were associated with central placenta and 2 $(1.9 \%)$ with lateral placenta.

Among 31 babies with IUGR (intrauterine growth restriction), $13(6.67 \%)$ were associated with central 
placenta and $18(17.14 \%)$ were associated with lateral placenta.

Among 27 LBW (low birth weight) babies 16 (8.21\%) were related to central placenta and $11(10.48 \%)$ were related to lateral placenta.

These 3 findings are elaborated in Table 3. P-value 0.022 .
Among 57 SNCU (sick new-born care unit) admissions $26(13.33 \%)$ were related to central placenta and 31 $(29.52 \%)$ were related to lateral placenta. P-value 0.001 . This is depicted in Table 4.

Average Birth-weight is $2.6 \pm 0.31 \mathrm{~kg}$ and $2.51 \pm 0.26 \mathrm{~kg}$ respectively for central and lateral placenta. P-value is 0.012 . This is illustrated in Table 5.

Table 4: Relation between placental location and SNCU admission.

\begin{tabular}{|c|c|c|c|c|c|c|}
\hline & & Placental lo & & & & \\
\hline & & Central & Lateral & Iotal & p-value & Significance \\
\hline SNCU admiccion & No & $169(86.67)$ & $74(70.48)$ & $243(81)$ & 0001 & Sionificant \\
\hline SIVCU aUIIISSSIOII & Yes & $26(13.33)$ & $31(29.52)$ & 57 (19) & 0.001 & SIginticant \\
\hline Total & & 195 (100) & $105(100)$ & $300(100)$ & & \\
\hline
\end{tabular}

Table 5: Relation between placental location and birth weight.

\begin{tabular}{|c|c|c|c|c|}
\hline & \multicolumn{4}{|c|}{ Placental location } \\
\hline & Central & Lateral & & \\
\hline & Mean \pm SD & Mean \pm SD & p-value & Significance \\
\hline Birth weight (kg) & $2.6 \pm 0.31$ & $2.51 \pm 0.26$ & 0.012 & Significant \\
\hline
\end{tabular}

Thus, it is clearly noted that lateral placenta is more commonly associated with poor perinatal outcome compared to central placenta.

\section{DISCUSSION}

Fetus is dependent on placenta for supply of nutrient from mother. Therefore, fetal growth is largely dependent on placental function. Position of placenta as determined by USG at 18-24 weeks of gestation can be an important determinant for predicting preeclampsia and perinatal outcome. When the placenta is laterally located, the uterine artery distal to the placenta has higher resistance than the one close to it because of less trophoblastic invasion. In patients with centrally located placentas both uterine arteries demonstrate similar resistance. It is possible that when the placenta is centrally located, the uteroplacental blood flow needs are met by equal contribution from both uterine arteries. However, when the placenta is laterally located, in the majority of patients the uteroplacental blood flow needs are to be met primarily by one of the uterine arteries with some contribution by the other uterine artery via collateral circulation. The degree of collateral contribution, however, may not be the same in all patients and deficient contribution may facilitate the development of preeclampsia or IUGR, or both. The pathophysiologic characteristics of preeclampsia are complex and the cause remains unknown. One of the fundamental disturbances in patients with this condition is decreased uteroplacental blood flow which is responsible for IUGR as well. Our data indicate that the presence of a unilateral placenta is strongly associated with preeclampsia. Preeclampsia and eclampsia are associated with perinatal complications like IUGR, IUFD and LBW babies. Last one is due to IUGR or preterm labour which may be spontaneous or iatrogenic. Studies are currently being conducted to evaluate the impact of aspirin in the prevention of preeclampsia. Further studies are necessary to evaluate the sensitivity of placental laterality and abnormal uterine artery flow velocity waveforms as a predictor of the development of preeclampsia and IUGR. If this proves to be the case, the use of aspirin in those patients who are at increased risk will help prevent or at least ameliorate some of the severe consequences of preeclampsia and may improve perinatal outcome as well.

In this study it was found that preeclampsia is more common with lateral placenta than central ones. P-value 0.000 which is statistically significant.

It is also evident from this study that eclampsia is also more common in pregnancies associated with lateral placentation. P-value is 0.003 which is statistically significant. It was noted that lateral placentation is responsible for perinatal complications like IUGR, IUFD and LBW. P-value is 0.022 which is statistically significant.

Lateral placenta also causes more SNCU admissions than central placenta. P-value is 0.001 which is again statistically significant. 
Lateral placental location is associated with lower BirthWeight compared to its counterpart. P-value (0.012) is statistically significant.

Kofinas AD et al, studied 153 pregnant women with normal pregnancies and 147 women with complicated pregnancies (diabetes, hypertensive disorders, and intrauterine growth retardation) in Winston-Salem, North Carolina to evaluate the association of placental location and the development of preeclampsia, intrauterine growth retardation, and uterine artery resistance. ${ }^{1}$ The placental location was determined by real-time ultrasonography, and the uterine artery resistance was determined by continuous-wave doppler flow velocity waveform analysis. In the presence of preeclampsia or intrauterine growth retardation, up to $75 \%$ of the patients had unilaterally located placentas and $25 \%$ central placentas, whereas in the absence of these two conditions only $51 \%$ of the patients had unilateral and $49 \%$ central placentas ( $p$ $<$ 0.02). In patients with unilateral placentas, the incidence of preeclampsia and intrauterine growth retardation was 2.8-fold and 2.7-fold greater than in patients with central placentas $(\mathrm{p}<0.03$ and $\mathrm{p}<0.01)$. Among all patient's unilateral placental location was more likely to be associated with abnormal uterine artery flow velocity waveforms than central placental location $(\mathrm{p}<0.001)$. They concluded that unilateral placental location may predispose to the development of preeclampsia and intrauterine growth retardation by its effect on uterine artery resistance.

Faizi S et al, conducted a prospective study on 620 women and placental location was determined by USG. ${ }^{2}$ Placental location was divided into 5 groups - anterior, posterior, fundal, low lying depending on where $>75 \%$ of placental mass is located. $274(44.1 \%)$ had anterior, $169(27.2 \%)$ had posterior,98 (15.8\%) had central, 61 $(9.8 \%)$ had lateral and $18(2.9 \%)$ had placenta praevia. It was found that IUGR was more common in lateral $(16.4 \%)$ and posterior placenta (16\%) although this association was not statistically significant. They concluded that lateral placental implantation was more commonly associated with preeclampsia and IUGR.

Kalanithi LEG et al, performed a case-control study in well-dated singleton pregnancies with $(n=67)$ and without $(\mathrm{n}=205)$ IUGR (defined as estimated fetal weight $<10^{\text {th }}$ percentile for gestational age at the last sonographic examination) to investigate the association between IUGR and placental location. ${ }^{3}$ Placental location was determined by sonography at 16 to 20 weeks' gestation. Maternal, perinatal, and delivery characteristics were abstracted from medical records. Group comparisons were made by the student t-test, $\chi 2$ analysis, the Fisher exact test, the Wilcoxon test, and analysis of variance. Multivariable logistic regression analysis was used to determine the relationship between IUGR and placental location. In both groups, the most common placental locations in the second trimester were anterior and posterior. After adjusting for potential confounders (including race, chronic hypertension, and hypertensive disorders of pregnancy), IUGR pregnancies were nearly 4-fold more likely to have lateral placentation (odds ratio, 3.8; 95\% confidence interval, 1.3-11.2) compared with anterior or posterior placentation. They concluded that pregnancies complicated by IUGR are significantly more likely than non-IUGR pregnancies to have lateral placentation in the second trimester.

Magann EF et al, concluded that high lateral implantations had a greater risk of low 1-min (OR 1.80, $95 \% \mathrm{CI} 1.11$ to $2.93, \mathrm{P}=0.017$ ) and 5 -min (OR 3.49, $95 \%$ CI 1.46 to $8.36, \mathrm{P}=0.005)$ Apgar scores. ${ }^{4}$

Seadati $\mathrm{N}$ et al, however could not find any association between placental location and IUGR or preeclampsia. ${ }^{5}$

Gupta V et al, conducted a study on 100 subjects. 28 had lateral placentas (L), 39 had centrally located placentas (C) and 33 had placentas on one side but crossing midline. ${ }^{6}$ It was noted that in all the 28 (24 out of 96 patients and 4 extra) patients of 'lateral' placenta group, the ipsilateral S/D (systole/diastole) was lower than contralateral S/D and the difference of S/D ratios of the two sides turned out to be statistically significant. Increased S/D ratio is associated with IUGR.

Devarajan $\mathrm{K}$ et al, did not find any association between placental location and development of IUGR or Preeclampsia.?

Liberti $\mathrm{M}$ et al, concluded that in patients with laterally implanted placentas a mean of both uterine arteries RI (resistance indices) above the $90^{\text {th }}$ centile and the presence of a diastolic notch in the placental uterine artery at 22-24 weeks have a higher predictive value for the subsequent development of PIH and IUGR than the separate evaluation of the 2 uterine arteries. ${ }^{8}$

Placental location and flow velocity waveforms of uterine arteries in 86 normal and 20 IUGR cases from 33 to 38 weeks of gestation were examined using a combined realtime scanner and pulsed Doppler ultrasonography by Ito Y et al. ${ }^{9}$ They found that Deviation of RIs in uterine arteries with IUGR could be affected by the pathologic conditions of the utero-placental blood flow on the placental side of lateral placenta rather than in central placenta and might be done by dramatic increase in resistance to flow of the myometrial vessels on the nonplacental side.

Study conducted by Jaiswal $\mathbf{J}$ et al, found that perinatal outcome was almost same for both the group and was not statistically significant. ${ }^{10}$ Mean value for gestational age in weeks, birth weight in $\mathrm{kgs}$, Apgar score at 1 and 5 minutes were almost similar for both central as well as lateral placentation, but mean duration of stay of baby in NICU was more in lateral placenta group i.e. 6 days versus 4 days. 
So, the result of our study regarding relationship between placental location on sonography and development of preeclampsia is similar to the findings of most of the aforementioned studies.

\section{CONCLUSION}

From our study, it is concluded that laterally located placenta on ultrasound done at $18-24$ weeks is associated with increased risk of development of preeclampsia and IUGR and other adverse pregnancy outcome like IUFD and LBW babies. Females with laterally located placenta require careful monitoring to achieve a more favourable outcome and decrease the maternal and perinatal morbidity and mortality associated with preeclampsia.

\section{ACKNOWLEDGMENTS}

Author would like to thank Dr. Mrinalkanti Ghosh, Associate Professor, Department of Radiodiagnosis, $\mathrm{BMCH}$, Burdwan for his active guidance, painstaking supervision, valuable advice and constant encouragement for this work.

Funding: No funding sources Conflict of interest: None declared

Ethical approval: The study was approved by the Institutional Ethics Committee

\section{REFERENCES}

1. Kofinas AD, Penry M, Swain M, Hatjis CG. Effect of placental laterality on uterine artery resistance and development of preeclampsia and intrauterine growth retardation. AM J Obstet Gynecol. 1989;161:153-69.

2. Faizi S, Pai MV. Role of midtrimester localisation of placenta in predicting pregnancy outcome. Int J Infe Fetal Med. 2014;5(3):87-91.
3. Kalanithi LEG, Illuzzi JL, Nossov VB, Frisbæk YR, Abdel-Razeq S, Copel JA, et al. Intrauterine growth restriction and placental location. Am Institute $\mathrm{J}$ Ultrasound Med. 2007;26:1481-9.

4. Magann EF, Doherty DA, Turner K, Lanneau GS Jr, Morrison JC Newnham JP. Second trimester placental location as a predictor of an adverse pregnancy outcome. J Perinatol. 2007;27:9-14.

5. Seadati N, Najafian M, Cheraghi M, Mohammadi B. Placental location at second trimester and pregnancy outcomes. JPSI2. 2013;2013:32-4.

6. Gupta V, Agarwal N. Correlation between placental location and uterine artery flow waveforms in uncomplicated pregnancies. JIMSA. 2014;27(1):178.

7. Devarajan K, Kives S, Ray JG. Placental location and newborn weight. J Obstet Gynaecol Can. 2012;34(4):325-9.

8. Liberti M, Rotmensch, Zannolli P, Perrino S, Celentano C, Tiboni GM, et al. Uterine artery Doppler velocimetry in pregnant women with lateral placenta. J Perinat Med. 1997;25:133-8.

9. Ito Y, Shono H, Shono M, Muro M, Uchiyama A, Sugimori H. Resistance index of uterine artery and placental location in intrauterine growth retardation. Acta Obstet Gynecol Scand. 1998;77:385-90.

10. Jaiswal J, Jaiswal A, Nagaria T, Ramteke A. Prediction of pregnancy induced hypertension by USG guided placental localization. J Evol Med Dent Sci. 2015;4(81):14163-72.

Cite this article as: Ghosh A, Ghosh M. A study on correlation between laterality of placenta on mid trimester ultrasonography and perinatal outcome. Int J Reprod Contracept Obstet Gynecol 2020;9:200-4. 